\title{
Adaptation to displaced vision-the influence of distribution of practice on retention ${ }^{1}$
}

\section{ROBERT DEWAR ${ }^{2}$ UNIVERSITY OF CALGARY}

\begin{abstract}
Subjects pointed to a target viewed through a laterally displacing wedge prism that gradually varied in strength from 0 to 20 diopters over a series of 42 trials. Trials were administered under conditions of massed or distributed practice. The aftereffect that resulted was measured immediately after exposure to the prism and at intervals of 2, 4, 6, 8, 10, and $15 \mathrm{~min}$. Distributed practice led to a gradual decrease in the aftereffect following prism exposure, whereas the massed practice condition produced a rapid decrease followed by a slight increase in the aftereffect.
\end{abstract}

Adaptation to displaced vision can be considered a perceptual learning process (Wohlwill, 1966). Some of the principles that govern other types of learning (verbal, motor skills, etc.) have been shown to apply to this adaptation process. Still others remain to be examined as they relate to the phenomenon. One such variable that has been shown to influence learning and retention is the distribution of practice. In general, material learned by spaced or distributed practice is retained better than that learned by massed practice, although for short retention intervals and for certain types of learning tasks there are exceptions to this general rule. The relevant literature will not be reviewed here since summaries are readily available elsewhere (e.g., McGeoch \& Irion, 1952, Hall, 1966).

Goldberg, Taub, and Berman (1967) examined "decay of prism aftereffect" and discovered a reminiscence phenomenon similar to that in motor skills learning. Following exposure to a wedge prism, the aftereffect increased to a maximum after about $11 \mathrm{~min}$ and then declined gradually (as determined by repeated measures on each S) to about zero after $90 \mathrm{~min}$. Hamilton and Bossom (1964) demonstrated that prismatic aftereffects of this type decay substantially even when the $S$ sits for $15 \mathrm{~min}$ in the dark following 15-min exposure to a wedge prism. Thr aftereffect will, of course, decay fairly quickly if $S$ receives reafferent stimulation (active visual-motor feedback). In fact, procedures involving this, such as bouncing a ball, are used in experiments in which Ss take part in more than one condition. This serves to remove the aftereffect produced by one condition before proceeding to the next.

Goldberg and Taub (1968) report a greater prism-induced aftereffect following distributed practice than after massed practice. Under the distributed practice condition, there was a considerable decrease in the aftereffect up to about $20 \mathrm{~min}$ following prism exposure, after which the aftereffect reached asymptote. The decay was somewhat more gradual for the massed practice group. Two conditions of massed practice were used $-5 \mathrm{~min}$ of straight exposure to a wedge prism and $91 / 2 \mathrm{~min}$ of straight exposure. The distributed practice involved $30 \mathrm{sec}$ of exposure followed by a $30-\mathrm{sec}$ rest, then $30 \mathrm{sec}$ of exposure, etc., for a total time of $9 \frac{1}{2} \mathrm{~min}(5 \mathrm{~min}$ of exposure). There was no difference between the two massed practice conditions. From their figures, it appears as if during the first $15 \mathrm{~min}$ after removal of the prism there was an interaction between the distributed practice and the 5-min straight massed practice groups (although they do not report or comment on this particular point). It is of interest to note that in this experiment the reminiscence phenomenon previously reported (Goldberg et al, 1967) was not found.

The purpose of this experiment was to examine the influence of the distribution of practice on adaptation to displaced vision and retention of this adaptation.

\section{SUBJECTS}

The Ss were volunteer male prisoners from the Calgary Provincial Jail. The average age was 21.2 years (ranging from 16 to 35 ).

\section{APPARATUS}

The apparatus was a modification of that used by Goldberg et al (1967). It was constructed of plywood, painted flat black, and set on a table of normal height. Attached to the front of the apparatus was a chinrest and a holder, in which was fixed a pair of modified welder's goggles, into which was fitted an American Optical Company rotary prism that was variable from 22 diopters left to 22 diopters right. The left eye was occluded by opaque material. Monocular vision was used because it tends to lead to greater adaptation and avoids some of the problems associated with convergence at close distances (Freedman \& Rekosh, 1968 , p. 159). The S's circular field of vision was approximately $30 \mathrm{deg}$ in diam. Eight inches in front of S's eye was a window that could be opened by $\mathbf{E}$. Ten inches beyond it was an identical window that could also be opened by E. Between the two windows (13 in. from S's eye) was a track along which the target (a 4-in., $1 / 4$-in. diam vertical wooden rod) could be moved horizontally. When the front window was open, $S$ could see only the target. When both windows were open, $S$ could see through to the back of the apparatus (a plain flat black background). On the underside of the apparatus was a scale that could be read to the nearest centimeter by viewing a reflection of the scale in a mirror on the table under the apparatus.

\section{PROCEDURE}

The $S$ was given a set of instructions to read and any questions about them were answered before the experiment began. The S's task was to locate the target that he viewed through the goggles by reaching under the apparatus with his right hand, to the index finger of which was attached an L-shaped pointer, so that the pointer came up at the back of the apparatus behind the target in line of sight with it. After each response, $S$ put his hand back on the table. $S$ kept the left hand on his lap at all times. At the beginning of each trial, the front window was closed, and the target was placed in one of six predetermined random positions. The front window was opened so that $S$ could see the target. He then made his response by reaching under the apparatus. Between trials, the front window was closed so that the target could be set at a new position. The experiment was carried out in three phases.

\section{Phase 1}

This stage consisted of blocks of seven trials, with the variable prism set at zero. During the first two trials, the back window was opened for approximately $1 \mathrm{sec}$ so that $S s$ received feedback regarding the correctness of their responses. During the last five trials of each block, the back window was not opened. Blocks of seven trials were administered until $S$ reached a criterion of a mean error of less than $1 \mathrm{~cm}$ 
on five consecutive trials without seeing his response. The mean error on those five trials constituted the preexposure measure of the S's ability to locate the target.

\section{Phase 2}

The S had a 30 -sec rest following the last trial of Phase 1 , during which he sat back in his chair with his eyes closed. During Phase 2, 42 trials were administered using the pacing procedure of Howard (1968), in which the prism strength is gradually increased. Ss were divided into two groups who received different practice conditions during this phase. The massed-practice group received all 42 trials in succession with no rest intervals (intertrial intervals were just long enough for $E$ to set the target for the next trial). The distributed practice group received trials in blocks of two, separated by a 2 -min rest interval, during which $S$ sat back in his chair with a blindfold on, while keeping his right hand on the table and his left hand on his lap. For all Ss, the first two trials were at a prism setting of 0 ; the next two were at a prism setting of 1 diopter, etc., with a 1-diopter increase in prism strength after every two trials, to a maximum lateral displacement of 20 diopters (approximately $11.3 \mathrm{deg}$ ). After each trial during all three phases, $E$ placed his fingers on the knob that adjusted the prism strength, even though adjustments were made only on every second trial of Phase 2 . This was done to reduce the likelihood of $S$ 's detecting a change in the prism strength because he suspected that $E$ was manipulating the prism. To reduce this possibility further, E placed a black shield before the prism after each trial so that $S$ could not detect visually the alteration being made in the prism. After $S$ had reached for the target, $E$ opened the back window so that $S$ could see the position of his pointer for approximately $1 \mathrm{sec}$. After the final trial, the prism was set at zero again.

\section{Phase 3}

The $S$ was immediately given two trials without knowledge of results. Further blocks of two trials were administered at the following intervals: $2,4,6,8,10$, and $15 \mathrm{~min}$ after Phase 2. Between blocks of trials, $S$ again sat back in his chair with a blindfold on, as in Phase 2 with the distributed practice group. The trials in
Phase 3 constituted the postexposure measure of the accuracy of localization of the target.

Half of the Ss in each group viewed the target with the prism base to the left and half with the base to the right. The difference between the preexposure and postexposure measures of localization constituted the aftereffect of the displaced vision. There were $20 \mathrm{Ss}$ in each group.

\section{RESULTS AND DISCUSSION}

An analysis of variance on the first 10 trials indicated no difference between distributed practice and massed practice $(F=0.45, \mathrm{df}=1 / 38, \mathrm{p}>.25)$. There was, however, a decrease in aftereffect over time $(F=4.09, \mathrm{df}=5 / 190, \mathrm{p}<.001)$ and $a$ Practice by Time Interval interaction $(F=6.96, \mathrm{df}=5 / 190, \mathrm{p}<.001)$. The distributed practice group decreased steadily, following exposure to the wedge prism, whereas the massed practice group decreased rapidly and then increased slightly (Fig. 1).

These results differ from those of Goldberg and Taub (1968), who reported greater aftereffect following distributed practice. Their apparent interaction between type of practice and retention was in the opposite direction (more rapid decrement of the aftereffect following distributed practice) to the present results.

Some basic differences exist between the present experiment and that by Goldberg and Taub (1968). The latter experiment used a biteboard to immobilize the head. It also used continuous display of the S's arm, of the type used by Held and Hein (1958), as opposed to terminal display that is used in the present experiment and that was used by Goldberg et al (1967) when they demonstrated the reminiscence effect. In addition, the pacing method used in the present experiment may also account for some of the differences.

The lack of a reminiscence effect in both the study by Goldberg and Taub (1968) and the present experiment remains unexplained. Perhaps this effect was specific to the terminal display technique in combination with the more frequently used (nonpacing) procedure of exposure to displaced vision. Further research is under way to examine this possibility.

\section{REFERENCES}

FREEDMAN, S. J., \& REKOSH, J. H. The

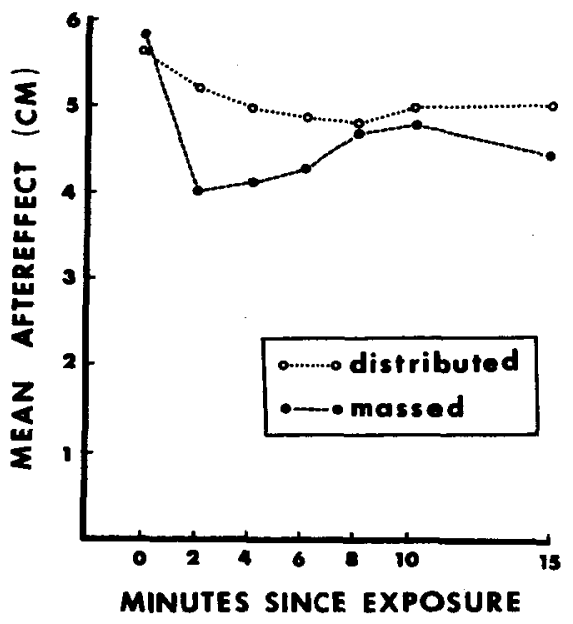

Fig. 1. Mean aftereffect as a function of type of practice during prism exposure and minutes since exposure.

functional integrity of spatial behavior. In S. J. Freedman (Ed.), The neuropsychology of spatially oriented behavior. Homewood, III: Dorsey Press, 1968. Pp. 153-162.

GOLDBERG, I. A., \& TAUB, E. Intermanual transfer of adaptation following "continuous display" of hand movements during prism exposure. Paper presented at Eastern Psychological Association meeting, Washington, D.C., April 1968.

GOLDBERG, I. A., TAUB, E., \& BERMAN, A. J. Decay of prism aftereffect and interlimb transfer of adaptation. Paper presented at Eastern Psychological Association meeting, Boston, April 1967.

HALL, J. F. The psychology of learning. Philadelphia: Lippincott, 1966.

HAMILTON, C. R., \& BOSSOM, J. Decay of prism aftereffects. Journal of Experimental Psychology, 1964, 67, 148-150.

HELD, R., \& HEIN, A. V. Adaptation of disarranged hand-eye coordination contingent upon reafferent stimulation. Perceptual \& Motor Skills, 1958, 8, 87-90.

HOWARD, I. P. Displacing the optical array. In S. J. Freedman (Ed.), The neuropsychology of spatially oriented behavior. Homewood, III: Dorsey Press, 1968. Pp. 19-36.

MCGEOCH, J. A., \& IRION, A. L. The psychology of human learning. New York: David McKay, 1952.

WOHLWILL, J. F. Perceptual learning. Annual Review of Psychology, 1966, 17, 201-232.

\section{NOTES}

1. This research was supported by National Research Council of Canada Grant No. APA 0141.

2. Address: Department of Psychology, The University of Calgary, Calgary 44, Alberta, Canada.

(Accepted for publication September 30, 1969.) 